\title{
Project Management and Transparency
}

\author{
JyotiM \\ Tata Consultancy Services ltd., Synergy Park, Non SEZ,Gacchibowli, Hyderabad
}

\begin{abstract}
Whether project is in manufacturing, maintenance, reengineering or any other field, transparency when applied to project management demonstrates the project as a textbook model and validates the team's achievements as unique and exemplary. The project becomes a classic model and sets the bar high. Transparency implies that in the hierarchy of management every employee will know what he or she needs to know to complete his or her part of the project.
\end{abstract}

Keywords: Project, transparency, stakeholders, organization, management

\section{Manuscript Body}

Project management comprises understanding the business 40 percent and 60 percent understanding the people involved in the business. Once the project manager gets the buy in of the stakeholders in the initiating stage, the stakeholders including the upper level management and the team members exhibit keen interest in the project. Since upper management is involved in the planning stage, once the charter is developed and the stakeholders are identified, the project manager needs to involve the upper management to the extent required while tackling project level problems. Transparency is utmost required in the planning stage. The ground rule is to let the customer know that the project manager is a staunch supporter of the project but frequent changes or scope creep may delay the project execution. During cost estimation, project managers must make contingencies for emergencies make sure that everything is accounted for and let the stakeholders know that the grass is not always green. Similarly risk quantification is important and overlooking side effects of risk can hit the project hard. Time management involves maintaining the database of success and failure stories apart from the daily reports as these stories are a reference bench mark for future projects.

Project manager should maintain transparency while hiring or firing a team member or even while the staff is voluntarily leaving. Special care should be taken when he is working with employees having physical disabilities. It is essential to give freedom to employees to work with creative genius yet keep a healthy distance between the project manager and the stakeholders while meeting the deadlines as this paves the way for successful project completion. Transparency in communication is of utmost importance for the project manager and especial care should be taken by the same while sending emails or addressing the staff in public meetings. Transparency in quality assurance is of importance too to enable the project manager to deliver and immaculate product. Transparency in conducting procurements is required as the process might call for an audit and can have big impact on the organization if any unethical processes are involved.

During monitoring and controlling phase project managers should watch and control the project with their eyes and ears fully open. There also needs to be a plan B for the project in case of any eventuality which should be known to the stakeholders and ready for implementation at a short notice. While project closure signoff is taken from the customer during the closing stage and lessons learned documented project managers should remember that just because a particular vendor did a great job in one project does not automatically mean that the vendor gets preferential treatment in the next project.

Centralised visibility of the project tasks, goals etc. and making them accessible to stakeholders are important at every stage of the project. Transparency can make the career of the manager but when not done properly can disconcert the project manager and his career in the long term.

\section{Conclusion}

By enabling a transparent project management system, everyone benefits from those working on the project to those sponsoring the project and auditing it. Usage of the system should be a priority for project leadership. Transparency with appropriate permissions in a project management system saves everyone on the project time and money. If transparency is lacking on a project, problems lurk and project management needs to investigate. The more knowledge someone has about the project, the easier it is to make a decision. A well designed project management system will allow for transparency from its inception. 


\section{References}

Channel World, International Journal of Information Technology and Management, International Journal Of Project Management

\section{Author's Information}

JyotiM, B.E, M.S. has got more than 25 years of work experience in IT industry with more than one and a half decade experience in project management. She has worked in various capacities from being a hands on technical person to project manager, program manager, portfolio manager to strategic business unit head mapping her portfolio to the changing trends in IT. 